\title{
ANALYSIS OF HARVARD MEDICAL SCHOOL COUNTWAY LIBRARY'S MOOC COURSE, BEST PRACTICES FOR BIOMEDICAL RESEARCH DATA MANAGEMENT: FOCUS ON THE EFFECTS OF COVID-19
}

Focusing on the enrollment period of 03/08/2020 - 07/08/2020

Kai Fay and Julie Goldman

Harvard Library

2021-08-27 


\section{Table of Contents}

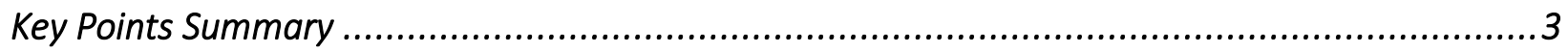

Introduction .............................................................................................. 4

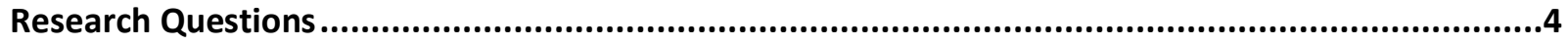

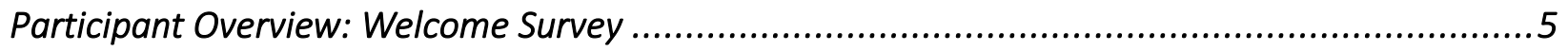

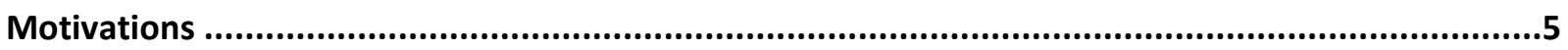

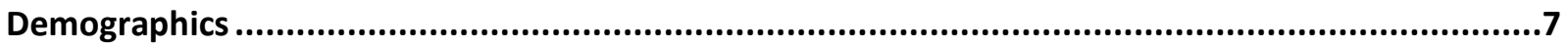

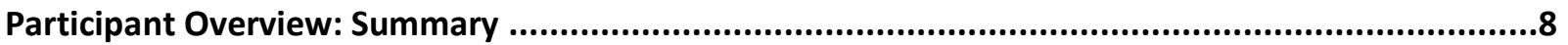

Course Participation and Completion Rate ........................................................ 8

Course Participation and Completion: Summary............................................................................

Participant Satisfaction: User Experience Survey .................................................. 9

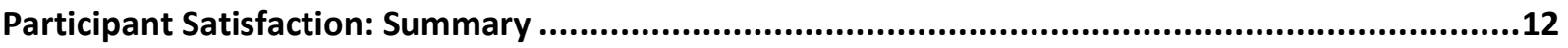

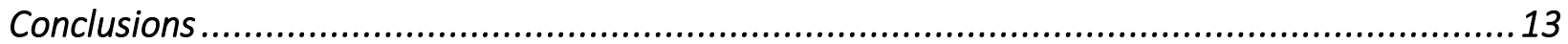

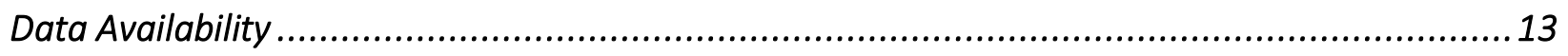

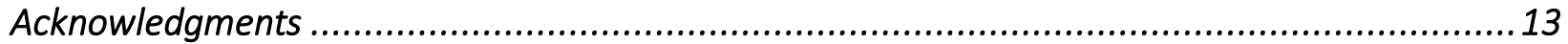

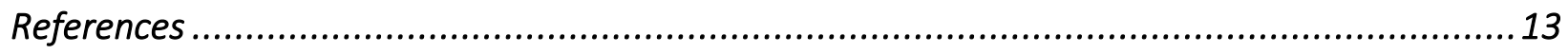

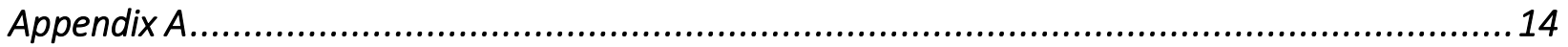

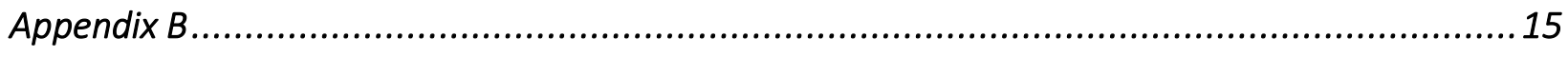

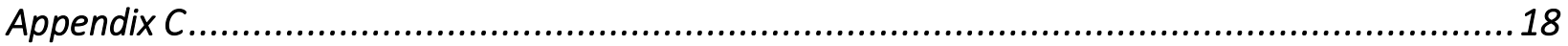




\section{Key Points Summary}

This report analyzes student reported data and course generated analytics from January 2018, through July 8, 2020, for the course Best Practices for Biomedical Research Data Management. By comparing the findings from the enrollment period through March 8, 2020 (pre-pandemic) to the period through July 8 , 2020 (during-pandemic), the main goal is to investigate potential shifts due to the COVID-19 pandemic.

Major findings include:

- The Welcome Survey was completed by 2,653 students between March 9, 2020 and July 8, 2020. During that time:

- The percentage of students completing the course increased by $3 \%$.

- The mean time taken to complete the course decreased by $60 \%$.

- Fifty-one students (2\%) cited the COVID-19 pandemic as a specific motivation for enrolling in the course.

- Students who joined during the first several months of the COVID-19 pandemic were a more diverse cohort across all analyzed metrics.

- The percentage of new students enrolling from North America decreased from $32 \%$ to $24 \%$.

- The percentage of new students enrolling from Asia/Pacific increased from $22 \%$ to $30 \%$.

- The percentage of new students enrolling from Sub-Saharan Africa decreased from $10 \%$ to $4 \%$.

- The percentage of new students indicating English as their primary spoken language decreased from $51 \%$ to $41 \%$.

- The percentage of new students who had completed graduate degrees decreased from $50 \%$ to $34 \%$.

- The percentage of new students whose highest education level was high school, or some college increased from $19 \%$ to $32 \%$.

- The User Experience Survey was completed by 435 students as of July 8, 2020:

- 344 (79\%) students provided reflections on how the course applied to their personal and professional goals:

- 96 students (27\%) reported gaining general knowledge.

- 118 students (34\%) reported the course's utility to their career.

○ 288 (66\%) students provided general feedback about the course content:

- Currency was a standout topic, as students highlighted the need for regular review of course content. 


\section{Introduction}

This report on the analysis of Harvard Medical School Countway Library's Massive Open Online Course (MOOC) Best Practices for Biomedical Research Data Management (Canvas Network n.d.), focuses on the potential effects of the COVID-19 pandemic. Building on previous work completed in summer 2019 (Trepanowski 2019), this report considers how student participation in the course may have shifted due to populations across the world being impacted by the pandemic.

\section{Research Questions}

\section{Participant Overview: Welcome Survey}

Research questions:

- Motivations:

- What is the highest education level of participants (pre-pandemic vs. during the pandemic)?

- What are the participants' motivations for enrolling in the course?

- Do students have a specific data management need they are trying to fulfill?

- Are students taking the course for their current or future job?

- Geographic:

- Where are the learners in the course coming from?

- Has location changed during the pandemic months?

- What are students' primary spoken language?

\section{Course Participation and Completion Rate}

Research questions:

- What percentage of students have completed the course?

- What are the characteristics of students that complete the course?

- How long did it take students to complete the course? Did this shift during the pandemic?

\section{Participant Satisfaction: User Experience Survey}

Research questions:

- What are students looking for in instructor involvement/engagement?

- How long of an online course do participants want?

- What do the students feel needs improvement?

- Are there lessons learned we can take away from this for creating an online course?

\section{Methods}

Raw data from the Welcome Survey, Course Assessment Survey, and User Experience Survey covering students who enrolled over the period from the beginning of the course Best Practices in Biomedical Research Data Management in January 2018 through July 8, 2020, was exported from the Canvas 
Network site and deidentified. Data contain unique participant IDs allowing for response and assessment data for individual students to be linked across course modules and surveys. Participants agreed to data use by Canvas and the instructors through the course service agreement.

Quantitative analysis was performed in Microsoft Excel, and qualitative analysis was performed in NVivo 12. Qualitative analysis was performed by a single coder using a mixed coding method. Codebooks are included in Appendix B, and survey questions are available in Appendix C. Open response data from course surveys was removed after coding and analysis to respect participant privacy. All quantitative analysis data files have been deposited in the Open Science Framework (Goldman \& Fay 2021).

\section{Participant Overview: Welcome Survey}

Students enrolling in the course must complete a Welcome Survey developed by the Canvas Instructure Team in order to unlock the main course modules. Welcome Survey response data was used to answer two categories of research questions:

- Motivations:

- What are the participants' motivations for enrolling in the course?

- Do students have a specific data management need they are trying to fulfill?

- Are students taking the course for their current or future job?

- Demographics:

- What is the highest education level of participants (pre-pandemic vs. during the pandemic)?

- Where are the learners in the course coming from?

- Has location changed during the pandemic months?

- What are students' primary spoken language?

From the start of the course in January 2018 through March 8, 2020, the Welcome Survey was completed by 1,054 students. In the four months from March 9, 2020, through July 8, 2020, the Welcome Survey was completed by 2,653 students. For the following sections, students who enrolled in the course but did not complete the Welcome Survey were not included in the analysis.

Data from the survey was used to produce visualizations that captured participants' motivation and goals for enrolling in the course and participant demographics including geographic location and primary language spoken.

\section{Motivations}

To evaluate students' motivations and goals in enrolling in the course, responses to the question "How will this course help you meet your personal or professional goals?" from the course Welcome Survey were analyzed and grouped according to the themes outlined below. Student motivations were wideranging, with the majority relating in some way to a career in the sciences or science education, but with a large minority also citing a personal interest in the topic or general interest in continued learning. 
A number of students also cited the COVID-19 pandemic as a motivation for enrolling in the course. The responses students gave relating to specific career goals and knowledge or skills had significant overlap with the responses given in the User Experience Survey about how this course helped students achieve their goals, so specific examples of those categories of responses will be given in the later section.

The target audience for this course is stated to be librarians, undergraduate and graduate students in biomedical majors, and biomedical researchers; however, responses to the Welcome Survey goals question showed a wider range of student backgrounds. In addition to those already in careers in the sciences, several students mentioned exploring career options to decide if biomedical research was a path they wished to pursue. For example, one student wrote, "this course could help me understand my interests so that when it is my time to go to college I will know what career I would like to study in." Other reasons students enrolled in the course ranged from being "a retired man looking for courses" to multiple students looking to "boost [their] self-confidence" to an educator who had "to build [their] own class using Canvas and wanted to see how some classes are structure[d]." For additional analysis of this category of response, see Appendix A. Finally, among students who cited the COVID-19 pandemic as a motivation for enrolling in the course, the specific situations mentioned ranged from cancelled summer internships and the suspension of in-person learning to adding new skills to a resume and learning to better manage research data in an all-online world. Although many students cited motivations that placed them within the intended audience for the course, other responses show that that audience was far from the only demographic represented, and in a course with thousands of students, even the smaller groups can represent a significant number of learners.

Table 1: Student motivations and goals grouped by themes.

\begin{tabular}{|l|l|}
\hline \multicolumn{2}{|l|}{ How will this course help you meet your personal or professional goals? (n=3267) } \\
\hline Career & 181 \\
\hline Career Exploration & 99 \\
\hline Current & 1157 \\
\hline Future & 714 \\
\hline Certificate/Harvard Name & 72 \\
\hline Don't Know Yet/It Won't & 62 \\
\hline Knowledge & \\
\hline General & 1370 \\
\hline Specific & 119 \\
\hline Skills & \\
\hline General & 573 \\
\hline Specific & 102 \\
\hline Pandemic & 51 \\
\hline Personal/General/Other Interest & 324 \\
\hline
\end{tabular}




\section{Demographics}

Prior to the COVID-19 pandemic, the majority (32\%) of students enrolling in the course were from North America with the next two largest groups being Asia/Pacific (22\%) and Europe (19\%). During the four months from March 9, 2020, through July 8, 2020, the percentage of new students enrolling from North America decreased to $24 \%$ (a $25 \%$ decrease). Students enrolling from Asia/Pacific saw the greatest increase to $30 \%$ of the total (a $36 \%$ increase) while Europe saw a smaller increase to $26 \%$ (a $37 \%$ increase). Students from Sub-Saharan Africa represented the largest percent change over the period with a $60 \%$ decrease from $10 \%$ of the total to $4 \%$. Sub-Saharan Africa is also the only region with a decrease in the absolute number of students joining the course in the four months in 2020 compared to the previous period.

Figure 1: Geographic breakdown of student locations (a) pre-March 9, 2020, and (b) March 9-July 8, 2020.

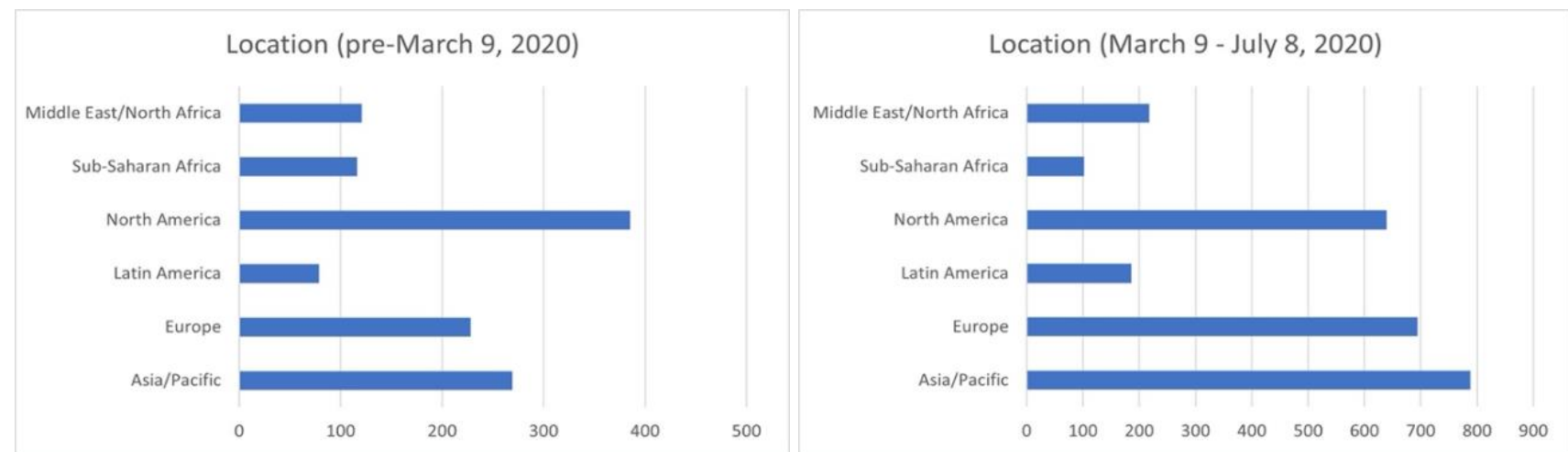

Among students who enrolled in the course prior to March 9, 2020, 51\% reported English as their primary spoken language while $49 \%$ did not. Among students who enrolled in the course in the four months from March 9, 2020, to July 9, 2020, 41\% of students reported English as their primary spoken language while $59 \%$ did not (a $20 \%$ decrease and $20 \%$ increase respectively).

Figure 2: Breakdown of students reporting English as their primary spoken language (a) pre-March 9, 2020, and (b) March 9-July 8, 2020.

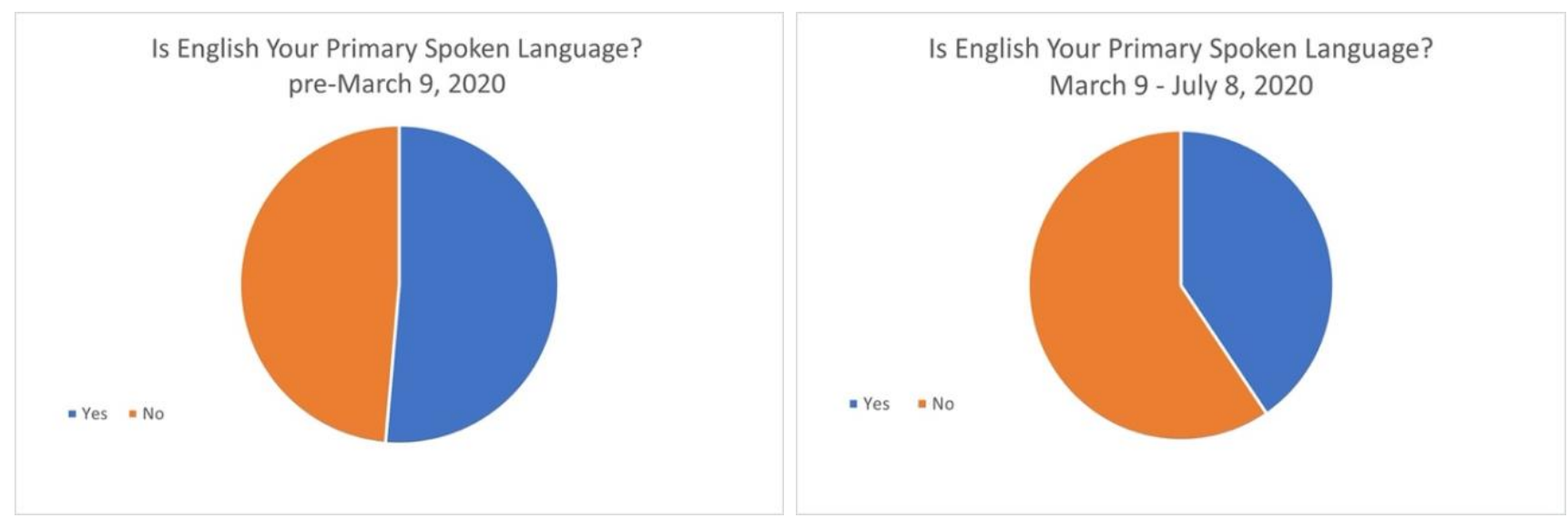


Prior to the COVID-19 pandemic, nearly half of the students enrolling in the course had completed a graduate degree, with $32.5 \%$ reporting a master's degree and $17.2 \%$ reporting a PhD, MD, or equivalent. During the four months from March 9, 2020, through July 8, 2020, the percentage of new students who had completed graduate degrees decreased to $34 \%$, and the percentage of new students whose highest education level was high school or some college increased from $19 \%$ to $32 \%$.

Figure 3: Breakdown of student' education level (a) pre-March 9, 2020, and (b) March 9-July 8, 2020.
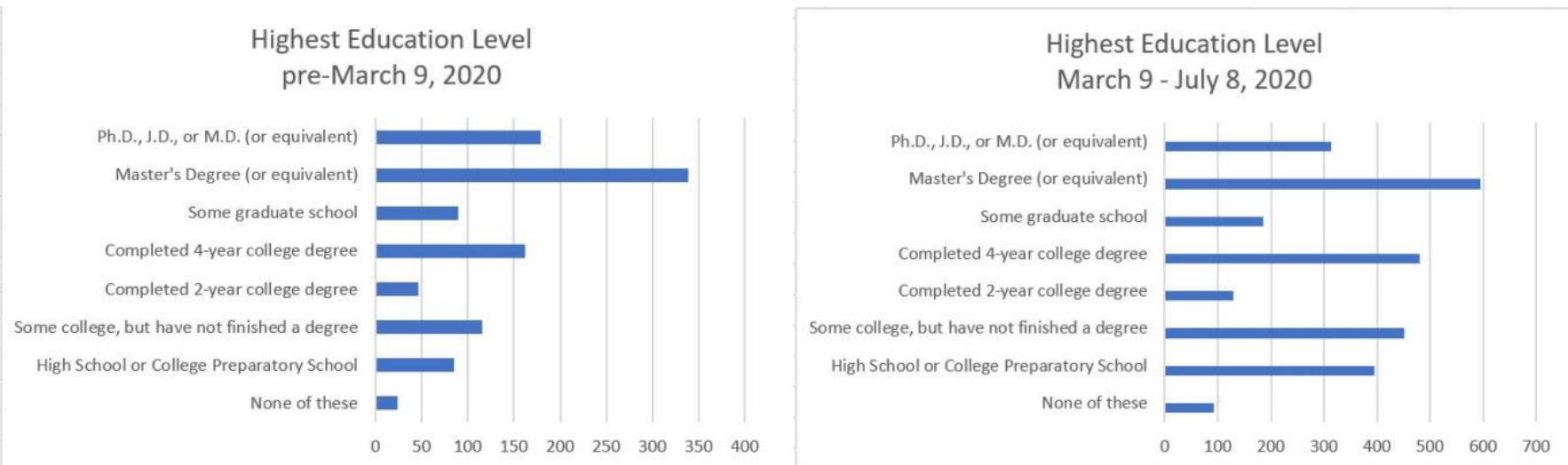

\section{Participant Overview: Summary}

Compared to the students who joined during the first 18 months (1.5 years) of the course, the students who joined during the first several months of the COVID-19 pandemic were a more diverse cohort across all analyzed metrics-geographic location, primary spoken language, and highest education level. During a period of significant restriction on normal life, students turned to this online course to improve the knowledge and skills they needed for their current careers, to better situate themselves for future careers in their desired field, or to explore areas of interest and potential future study. Although most students had some form of professional connection to the material covered, a smaller number joined out of a personal interest in exploring new topics.

An area for future research is analysis of the Welcome Survey question, "How did you hear about this Canvas Network course?" This question was not included in the analysis for this report, but responses would provide insight into how students were coming into the course. The analysis could be further refined by cross-referencing these responses to geographic location and analyzing smaller time intervals to identify more local trends among new students.

\section{Course Participation and Completion Rate}

Data from participants' Welcome Survey and Course Assessment date stamps were used to answer the following research questions:

- What percentage of students have completed the course?

- What are the characteristics of students that complete the course? 
- How long did it take students to complete the course? Did this shift during the pandemic?

In the period between the start of the course in January 2018 and March 8, 2020, 1,054 students enrolled in the course and completed the Welcome Survey. Of those students, 171 had completed the final Course Assessment Survey by October 15, 2020, for a completion rate of $16 \%$. In the four months from March 9, 2020, to July 9, 2020, 2,653 new students enrolled in the course and completed the Welcome Survey, and 493 had completed the course by October 15, 2020, for a completion rate of $19 \%$.

In the period prior to March 8, 2020, the mean time to completion among students who completed the course was 55 days (about 2 months), and the median time to completion was 13 days (about 2 weeks). The time to completion dropped significantly in the four-month period from March 9, 2020, to July 8 , 2020 , with the mean time to completion decreasing by $60 \%$ to 22 days (about 3 weeks) and the median time to completion decreasing $41 \%$ to 9 days.

\section{Course Participation and Completion: Summary}

Despite the shorter time, the percentage of students completing the course increased by $3 \%$ during the first four months of the COVID-19 pandemic when compared to the previous period. Due to the shorter duration used for analysis in the second case, a decrease in the time to completion was expected. However, the increased completion rate in conjunction with the decrease in both mean and median time to completion suggests that the observed change was not entirely due to the different lengths of the two time periods.

\section{Participant Satisfaction: User Experience Survey}

Research questions:

- Engagement:

- What are students looking for in instructor involvement/engagement?

- How long of an online course do participants want?

- In what ways has this course helped participants meet their personal or professional goals?

- Improvement:

- What do the students feel needs improvement?

- Are there lessons learned we can take away from this for creating an online course?

\section{Engagement}

During the User Experience Survey at the end of the course, students were asked the questions "How much instructor involvement do you like to have in your online learning experiences?" and "Ideally, how long should Canvas Network Courses last?" (Figure 4). For the first question, most students responded, "I like variety" with the second most common answer being "I like to learn on my own." Although the nature of asynchronous MOOCs, especially those such as this one with thousands of students, make 
one-on-one instructor interaction more difficult than in smaller or face-to-face classes, it does not preclude other forms of student interaction. This course was designed to give students multiple options for engaging with the material. The primary course content took the form of readings and pre-recorded videos, but discussion forums for each module gave students additional opportunities to engage with the course material and with one another. For the second question, the majority of students indicated a preferred length of 2-4 weeks with 4-6 weeks ( 1 to 1.5 months) being the second most common response. The preferred timeline reported by students was higher than the average actual completion times reported earlier.

One major limitation of this analysis is that it only surveys students who completed the course, so it does not capture the perspectives of students who may have dropped the course because it was not meeting their needs.

Figure 4: Reported student (a) preferred instructor involvement and (b) course length.

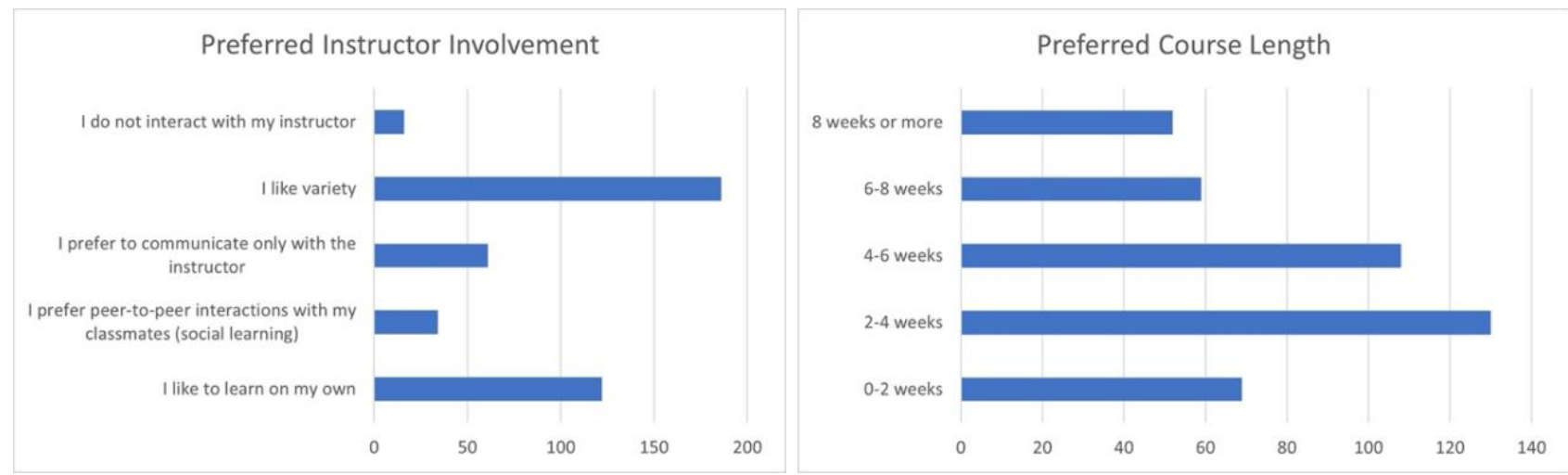

Prior to receiving a certificate of completion for the course, students were asked to complete a User Experience Survey. By July 9, 2020, 435 students had completed the survey and their answers to the free text question "In what ways has this course helped you meet your personal or professional goals?" were analyzed and grouped according to the themes outlined in Table 2 below. Blank responses, nonsense text, and responses that did not answer the question were excluded from the analysis.

The most common responses were about content learned in the course, which were further divided during analysis into knowledge and skills. Many of the responses about knowledge were general statements such as "helping me to understand how to manage research data," but about a quarter of the responses gave more specific examples such as "IPR rights and licensing policies" and "grants requirements and the process of getting a grant for research." A smaller number of students mentioned skills instead of knowledge, but they showed a similar ratio of general statements such as "increasing my skills" to specific statements such as "it helped me go back and save some of my preliminary data using naming conventions that I could understand."

The other significant category of responses was the course's utility to a career. Responses in this category were evenly divided between current careers and intended future career. The students who cited current careers gave examples of both ways in which the information helped them individually, and the ways they could apply it in their broader networks. For example, some students mentioned 
"what I need to be looking at and taking note of during my PhD research" and "important knowledge for [managing] the research data of my project," while others stated, "guide students in their data management handling processes" and "strongly coach and help students in science research." Others looked even more broadly, for example, "beginning the process of creating data management processes at my institution" or "how I could partner with research teams and the role I am to play in the team as a librarian." The students who cited utility to a future career included both students who had never done research before and saw the course as "help[ing them] begin that journey" and students who were currently engaged in research but found the course was helpful to "show on applications for medical or graduate school" and "present future research work more effectively."

Table 2: Student reflections on their goals grouped by themes (as identified earlier)

\begin{tabular}{|c|l|}
\hline In what ways has this course helped you meet your personal or professional goals? $(\mathbf{n}=\mathbf{3 4 4})$ \\
\hline Career & 26 \\
\hline Current & 46 \\
\hline Future & 46 \\
\hline Knowledge & \\
\hline General & 94 \\
\hline Specific & 35 \\
\hline Skills & \\
\hline General & 26 \\
\hline Specific & 9 \\
\hline Personal/General Interest & 16 \\
\hline It Has Not & 11 \\
\hline
\end{tabular}

\section{Improvement}

Student responses to the User Experience Survey question "If you'd like to provide any general feedback on the course, please do so here" were primarily generic positive statements such as "it was good;" however, the most useful responses were those that critiqued the course (Table 3). The critical feedback can be divided into three primary areas: currency, global relevance, and certificate issues. The third area was the easiest to address. This course used a free, automated tool to generate and send certificates to students upon completion. When the number of students enrolling in the course increased by nearly two orders of magnitude in the spring of 2020, the number of students completing the course significantly exceeded the monthly quota of the tool. Switching to a different tool with a higher quota resolved most of the certificate issues.

Currency will always be an issue in long-running courses, especially those in areas that are changing as rapidly as data management. Of the issues reported by students, some such as broken links, were simple fixes. Others, such as outdated information in the lecture videos would require more extensive effort to address. In all cases, student feedback highlighted the need for regular review of course content. Although some of the larger issues were not addressed, a regular, proactive review for broken links or 
superseded references would have prevented students from being the first ones to discover or report many of these issues.

Research data management is a global issue, and this course drew students from across the world. Despite that, this course was created by researchers based in the United States, which necessarily influences its perspective. Given the diversity of learners and the purpose of MOOCs in general as a tool to increase the accessibility of knowledge, an ideal goal would be to include more global examples and standards in the course. Limitations on time and funding frequently preclude attaining that ideal, so at the very least, the course should be explicit in defining the perspective it is speaking from so that students are aware of what will be covered, or not covered, from the start.

Table 3: Student provided feedback grouped by themes.

\begin{tabular}{|l|l|}
\hline \multicolumn{2}{|l|}{ If you'd like to provide any general feedback on the course, please do so here $(\mathbf{n}=\mathbf{2 8 8})$} \\
\hline Additional Courses & 12 \\
\hline Certificate & 4 \\
\hline Content & 46 \\
\hline \multicolumn{1}{|c|}{ Positive } & 24 \\
\hline Critique & 29 \\
\hline Goals/Career & 22 \\
\hline Generic Positive & 125 \\
\hline Platform & 9 \\
\hline
\end{tabular}

\section{Participant Satisfaction: Summary}

When students were asked how this course helped them achieve their goals, the most common answers were about increased knowledge and career success, with the latter covering both current and future careers. While career goals were a common theme among students, the specific careers spanned a broader area than the original expected audience for the course.

Despite their diverse goals, students expressed similar desires for overall course structure and length. Although the timing of the User Experience survey limited feedback only to students who completed the course, it provides general feedback that can be used to shape future online courses. Student feedback also highlighted areas where the current course suffered from outdated links or materials and highlighted the importance of developing a review schedule for online courses.

An area for future research is to compare the achieved goals reported by students at the end of the course to the goals they reported in the Welcome Survey. This analysis would investigate whether students' original goals were met by the course, if students with certain types of goals were more likely than others to complete the course, or if students went into the course with one expectation and left with a different need being met. Another area for additional analysis is to further subdivide the careerrelated responses to both the User Experience Survey and the Welcome Survey based on the type of career-student, researcher, instructor, etc. - to look at any trends in the types of careers that drew students to the course. 


\section{Conclusions}

The number of students enrolling in the course increased by nearly two orders of magnitude in the Spring of 2020, which correlates with the number of students directly citing the effects of COVID-19 pandemic as motivation for enrolling in the course. During a period of restrictions on in-person learning, students turned to this online course to improve the knowledge and skills they needed for their current careers, to better situate themselves for future careers in their desired field, or to explore areas of interest and potential future study.

The success of this course illustrates the value and utility of free online professional development as a tool for both library and research staff. In two and a half years, (from January 8, 2018, to July 8, 2020) the course successfully reached over 6,000 people from across the world, increased their understanding of data management topics, and successfully supported participants' learning goals. The success of this course shows how free online content can have an impact on RDM knowledge.

\section{Data Availability}

The datasets generated and/or analyzed during the current study are available in Open Science Framework at https://osf.io/tykqc (Goldman \& Fay 2021).

\section{Acknowledgments}

This project is led by the Francis A. Countway Library of Medicine at the Harvard Medical School, made possible by funding from the NIH Big Data to Knowledge (BD2K) Initiative for Resource Development (Award Number R25LM012284).

The authors would like to thank Ceilyn Boyd for her insights on structuring the data analysis for the Canvas dataset and reviews of this report and Melanie Smith for input and feedback on the qualitative methodology.

\section{References}

Canvas Network. n.d. "Best Practices for Biomedical Research Data Management." Accessed April 26, 2021. https://www.canvas.net/browse/harvard-medical/courses/biomed-research-data-mgmt

Goldman, Julie, and Kai Fay. 2021. "Analysis Data: Focus on the Effects of COVID-19." OSF. https://osf.io/tykqc

Trepanowski, Nevada. 2019. "Analysis of Harvard Medical School Countway Library's MOOC Course: Best Practices for Biomedical Research Data Management." [Unpublished Report]. 


\section{Appendix A}

Further subdivisions of the "Personal/General Interest/Other" category in responses to the Welcome Survey question "How will this course help you meet your personal or professional goals?" These numbers represent very small subsets of the total student population $(<0.5 \%)$, but an area for future research would be to evaluate these motivations across additional students who joined the course after the period covered in this analysis to see if similar trends emerge.

\begin{tabular}{|l|l|}
\hline English vocabulary and communication & 16 \\
\hline Evaluating to assign & 8 \\
\hline Filling gaps & 8 \\
\hline Online instruction/pedagogy & \\
\hline$\quad$ Instructor & 15 \\
\hline Student & 9 \\
\hline Required & 6 \\
\hline Self-confidence & 16 \\
\hline
\end{tabular}




\section{Appendix B}

Codebook for responses to Welcome Survey question "How will this course help you meet your personal or professional goals?"

\begin{tabular}{|c|c|}
\hline \multicolumn{2}{|c|}{ How will this course help you meet your personal or professional goals? } \\
\hline Career & $\begin{array}{l}\text { For all career codes, "career" also includes any references to enrollment } \\
\text { in academic programs (e.g., "useful for a current/future academic } \\
\text { degree"). The top-level code is used for responses that refer to a career } \\
\text { but include no indication of whether it is a current career or a future } \\
\text { aspiration. }\end{array}$ \\
\hline Career Exploration & References to exploring a potential degree/career. \\
\hline Current & References to a current job or academic program. \\
\hline Future & $\begin{array}{l}\text { References to desired future jobs, including both specific examples and } \\
\text { general statements. Includes references to listing the course on a } \\
\text { resume but excludes references to receiving the certificate of } \\
\text { completion. }\end{array}$ \\
\hline Certificate/Harvard Name & $\begin{array}{l}\text { References to the certificate offered for completing the course or to } \\
\text { enrolling in the course due to Harvard's status/name recognition. }\end{array}$ \\
\hline Don't Know Yet/It Won't & $\begin{array}{l}\text { References to not knowing how the course will help a student meet their } \\
\text { goals, or indication that the course will not help a student meet any of } \\
\text { their current goals. }\end{array}$ \\
\hline Knowledge & $\begin{array}{l}\text { All knowledge codes include explicit references to knowledge as well as } \\
\text { any references to concepts covered in the course. The top-level } \\
\text { knowledge code is not used. }\end{array}$ \\
\hline General & $\begin{array}{l}\text { General references to knowledge (e.g., "expand my knowledge") as well } \\
\text { as references to overall concepts (e.g., "learn more about biomedical } \\
\text { research data management"). }\end{array}$ \\
\hline Specific & References to specific concepts/topics. \\
\hline Skills & $\begin{array}{l}\text { All skill codes include explicit references to skills as well as any } \\
\text { references to tools/procedures being applied in a research environment. } \\
\text { The top-level skills code is not used. }\end{array}$ \\
\hline General & General references to skills (e.g., "learn new skills"). \\
\hline Specific & $\begin{array}{l}\text { References to specific applicable skills (e.g., "how to use an electronic } \\
\text { lab notebook to organize my research data"). }\end{array}$ \\
\hline Pandemic & $\begin{array}{l}\text { Explicit references to the COVID-19 pandemic as well as any responses } \\
\text { that could reasonably be inferred to be in reference to the COVID-19 } \\
\text { pandemic (e.g., "my planned summer research internship was cancelled } \\
\text { like everything else this year") }\end{array}$ \\
\hline $\begin{array}{l}\text { Personal/General } \\
\text { Interest/Other }\end{array}$ & $\begin{array}{l}\text { References to non-academic/career reasons for enrolling in course. Does } \\
\text { not include responses that do not answer the original survey question. }\end{array}$ \\
\hline
\end{tabular}




\begin{tabular}{|c|l|}
\hline $\begin{array}{c}\text { English vocabulary and } \\
\text { communication }\end{array}$ & $\begin{array}{l}\text { References to a desire to learn the vocabulary and terminology to better } \\
\text { communicate on this topic in English. }\end{array}$ \\
\hline Evaluating to assign & $\begin{array}{l}\text { References to considering whether to assign this course to an } \\
\text { individual's own students/researchers/department/etc. }\end{array}$ \\
\hline Filling gaps & $\begin{array}{l}\text { Includes only references to instruction on this topic not being offered by } \\
\text { a student's home institution/country. Does not include more general } \\
\text { references to identifying gaps in knowledge that a student wishes to fill. }\end{array}$ \\
\hline $\begin{array}{c}\text { Online } \\
\text { instruction/pedagogy }\end{array}$ & $\begin{array}{l}\text { References specifically to teaching/learning in an online environment. } \\
\text { Does not include references to teaching in general. Only the two } \\
\text { subcodes are used. }\end{array}$ \\
\hline Instructor & $\begin{array}{l}\text { References to online teaching/pedagogy from the instructor perspective, } \\
\text { including references to course design/assessment. }\end{array}$ \\
\hline Student & $\begin{array}{l}\text { Includes both references to the online learning environment in general } \\
\text { and to students looking for a different perspective/approach to content } \\
\text { they already learned. }\end{array}$ \\
\hline Required & $\begin{array}{l}\text { References to the course being assigned as a requirement for a } \\
\text { job/class/degree. }\end{array}$ \\
\hline Self-confidence & $\begin{array}{l}\text { References to enrolling in the course to increase confidence overall } \\
\text { and/or in specific areas. }\end{array}$ \\
\hline
\end{tabular}

Codebook for responses to User Experience Survey question "In what ways has this course helped you meet your personal or professional goals?"

\begin{tabular}{|l|l|}
\hline \multicolumn{2}{|l|}{ In what ways has this course helped you meet your personal or professional goals? } \\
\hline Career & $\begin{array}{l}\text { For all career codes, "career" also includes any references to enrollment } \\
\text { in academic programs (e.g., "useful for a current/future academic } \\
\text { degree"). The top-level code is used for responses that refer to a career } \\
\text { but include no indication of whether it is a current career or a future } \\
\text { aspiration. }\end{array}$ \\
\hline Current & References to a current job or academic program. \\
\hline Future & $\begin{array}{l}\text { References to desired future jobs, including both specific examples and } \\
\text { general statements. Includes references to listing the course on a } \\
\text { resume but excludes references to receiving the certificate of } \\
\text { completion. }\end{array}$ \\
\hline Knowledge & $\begin{array}{l}\text { All knowledge codes include explicit references to knowledge as well as } \\
\text { any references to concepts covered in the course. The top-level } \\
\text { knowledge code is not used. }\end{array}$ \\
\hline General & $\begin{array}{l}\text { General references to knowledge (e.g., "expand my knowledge") as well } \\
\text { as references to overall concepts (e.g., "learn more about biomedical } \\
\text { research data management"). }\end{array}$ \\
\hline Speferences to specific concepts/topics. \\
\hline
\end{tabular}




\begin{tabular}{|c|l|}
\hline Skills & $\begin{array}{l}\text { All skill codes include explicit references to skills as well as any } \\
\text { references to tools/procedures being applied in a research environment. } \\
\text { The top-level skills code is not used. }\end{array}$ \\
\hline General & General references to skills (e.g., "learn new skills"). \\
\hline Specific & $\begin{array}{l}\text { References to specific applicable skills (e.g., "how to use an electronic } \\
\text { lab notebook to organize my research data"). }\end{array}$ \\
\hline Personal/General Interest & $\begin{array}{l}\text { References to non-academic/career reasons for enrolling in course. } \\
\text { Does not include responses that do not answer the original survey } \\
\text { question. }\end{array}$ \\
\hline It Has Not & References to the course not helping a student reach their goals. \\
\hline
\end{tabular}

Codebook for responses to User Experience Survey question "If you'd like to provide any general feedback on the course, please do so here."

\begin{tabular}{|l|l|}
\hline If you'd like to provide any general feedback on the course, please do so here \\
\hline Additional Courses & $\begin{array}{l}\text { References to interest in additional similar (online) courses on related } \\
\text { topics. }\end{array}$ \\
\hline Certificate & $\begin{array}{l}\text { References to difficulties receiving the certificate after completing the } \\
\text { course. Does not include any other references to certificates. }\end{array}$ \\
\hline Content & $\begin{array}{l}\text { References to content covered in the course. Includes any feedback on } \\
\text { course structure/activities but does not include feedback on the } \\
\text { software/platform used for the course. All references to content are } \\
\text { coded into the top-level code and any applicable subcodes. }\end{array}$ \\
\hline \multicolumn{1}{|c|}{ Positive } & Positive feedback on the course content. \\
\hline Critique & Critical feedback on course content. \\
\hline Goals/Career & References to the effect of the course on a student's goals or career. \\
\hline Generic Positive & $\begin{array}{l}\text { Generic positive feedback on the course that does not provide } \\
\text { additional details (e.g., "I enjoyed it"/"I learned a lot"). }\end{array}$ \\
\hline Platform & $\begin{array}{l}\text { Specific references to Canvas Network, by name or by clearly identifying } \\
\text { description (e.g., "this online course platform"). }\end{array}$ \\
\hline
\end{tabular}




\section{Appendix C}

Welcome Survey (Required by Canvas Network)

141829: What is your primary reason for taking an open online course?

- I like the format (online)

- I enjoy learning about topics that interest me

- I enjoy being part of a community of learners

- I hope to gain skills for a new career

- I hope to gain skills for a promotion at work

- I am preparing to go back to school

- I am preparing for college for the first time

- I am curious about MOOCs

- I want to try Canvas Network

141830: Not everyone has the same participation and learning goals. We welcome the diversity. Which type of online learner best describes you?

- An observer. I just want to check the course out. Count on me to "surf" the content, discussions, and videos but don't count on me to take any form of assessment.

- A drop-in. I am looking to learn more about a specific topic within the course. Once I find it and learn it I will consider myself done with the course.

- A passive participant. I plan on completing the course but on my own schedule and without having to engage with other students or assignments.

- An active participant. Bring it on. If its in the course, I plan on doing it.

141831: How many hours a week are you planning to spend on this course?

- Less than 1 hour

- Between 1 and 2 hours

- Between 2 and 4 hours

- Between 4 and 6 hours

- Between 6 and 8 hours

- More than 8 hours per week

141832: How will this course help you meet your personal or professional goals? [open ended]

141833: What is your highest level of education?

- High School or College Preparatory School

- Some college, but have not finished a degree

- Completed 2-year college degree

- Completed 4-year college degree

- Some graduate school 
- Master's Degree (or equivalent)

- Ph.D., J.D., or M.D. (or equivalent)

- None of these

141834: Is English your primary spoken language?

- Yes

- No

141835: Where do you live?

- North America

- Latin America

- Europe

- Middle East/North Africa

- Sub-Saharan Africa

- Asia/Pacific

141836: What is your gender?

- Male

- Female

- Other

141837: How old are you?

- $13-18$

- $19-24$

- 25-34

- $35-44$

- $45-54$

- 55-64

- 65 or older

141838: How did you hear about this Canvas Network Course? (select all that apply)

- Through a social media site (like Facebook or Twitter)

- From a news story (print, online, radio, or TV) that mentioned the course and/or Canvas Network

- From a friend or colleague

- I clicked on an ad

- From a web search

- From the instructor

- From a Canvas or Canvas Network communication

- From the sponsoring institution (newsletter, institution's website/blog, or flyer) 
141839: Where have you taken an online course before? (Select all that may apply)

- Never taken an online course

- At school

- Canvas Network

- Coursera

- $\mathrm{EdX}$

- Udacity

- FutureLearn

- Other

141840: If you have any general feedback you'd like to provide, please do so here: [open ended]

User Experience Survey (Required by Canvas Network)

141842: How strongly do you agree or disagree with the following statement: The course materials (lectures, videos, documents) have a positive impact on my learning experience.

- Strongly Disagree

- Disagree

- Neither Agree nor Disagree

- Agree

- Strongly Agree

141843: How strongly do you agree or disagree with the following statement: The course activities (discussions, assignments, projects, quizzes) have a positive impact on my learning experience.

- Strongly Disagree

- Disagree

- Neither Agree nor Disagree

- Agree

- Strongly Agree

141844: How many hours a week are you spending on this course?

- Less than 1 hour

- Between 1 and 2 hours

- Between 2 and 4 hours

- Between 4 and 6 hours

- Between 6 and 8 hours

- More than 8 hours per week

141845: In what ways has this course helped you meet your personal or professional goals? [open ended] 
141846: How likely are you to recommend a course on Canvas Network to a friend?

- 0 - Not Likely

- 1

- 2

- 3

- 4

- 5 - Neutral

- 6

- 7

- 8

- 9

- 10 - Extremely Likely

141847: Please give this course an overall rating on a scale of 1 to 5 with 1 being the lowest and 5 being the highest rating.

- 1 star

- 2 stars

- 3 stars

- 4 stars

- 5 stars

141848: How much instructor involvement do you like to have in your online learning experiences?

- I like to learn on my own

- I prefer peer-to-peer interactions with my classmates (social learning)

- I prefer to communicate only with the instructor

- I like variety

- I do not interact with my instructor

141849: Ideally, how long should Canvas Network Course last?

- $0-2$ weeks

- 2-4 weeks

- 4-6 weeks

- 6-8 weeks

- 8 weeks or more

141850: How strongly do you agree or disagree with the following statement? I have a positive user experience when I access my course on my smartphone (e.g. iPhone, Android phone).

- I do not use a smartphone to access my course

- Strongly Disagree

- Disagree 
- Neither Agree nor Disagree

- Agree

- Strongly Agree

141851: How strongly do you agree or disagree with the following statement? I have a positive user experience when I access my course on my tablet device (e.g. iPad, Nexus).

- I do not use a tablet device to access my course

- Strongly Disagree

- Disagree

- Neither Agree nor Disagree

- Agree

- Strongly Agree

141852: If you'd like to provide any general feedback on the course, please do so here: [open ended] 